\title{
Refined Multiphysics Analysis of W7-X Cryopumps
}

\author{
Jiawu Zhu*, Victor Bykov, Michael Nagel, Gunnar Ehrke, Joris Fellinger, Lutz Wegener,
} Hans-Stephan Bosch and W7-X team

Max-Planck-Institut für Plasmaphysik, D-17491 Greifswald, Germany

(Dated: 18 April 2018)

\begin{abstract}
Ten identical cryopumps (CVP) are to be installed in corresponding divertor volumes of Wendelstein 7-X (W7$\mathrm{X}$ ) stellarator before commencing the steady state phase of operation (OP 2). Each CVP is typically made of two units connected by a transfer line and is fed through a dedicated vacuum vessel feed through. The units consist of water baffle, liquid nitrogen (LN2) baffle, helium panel and LN2 cooled housing. All components are expected to be well cooled with the available cooling capacity during long pulse plasma operation in order to maintain the helium panel at about $4 \mathrm{~K}$ and hence ensure the desired absorption rate. The LN2 cooled housing has to minimize both the effect of electron-cyclotron resonance heating (ECRH) and the thermal radiation from backside of in-vessel components on the $80 \mathrm{~K} \mathrm{CVP}$ shield elements. Moreover, the ECRH is unevenly distributed in W7-X which requires analyses of several cases and sophisticated cooling scheme as described. The paper presents thermal behavior of CVP components and is followed by the discussion of several important issues for assessment. In addition, eddy current and electromagnetic (EM) forces on CVP copper components are analyzed for the events of fast discharge of main superconducting coils, plasma current decay, alternating current in control coils and fast discharge of trim coils. Moreover, sharing of eddy currents between plasma vessel shell and attached CVP is estimated. Structural analysis taking temperature gradients and EM forces into account indicates that the mechanical performance is acceptable.
\end{abstract}

Keywords - Wendelstein 7-X (W7-X), stellarator, cryopump, thermal analysis, electromagnetic analysis, eddy current, structural analysis.

\section{ABBREVIATIONS}

$\begin{array}{ll}\text { ac } & \text { alternating current } \\ \text { BM } & \text { baffle modules } \\ \text { BS } & \text { backside protection } \\ \text { CVP } & \text { cryo vacuum pumps } \\ \text { DCU } & \text { divertor cryopump unit } \\ \text { EM } & \text { electromagnetic } \\ \text { ECRH } & \text { electron-cyclotron resonance heating } \\ \text { FD } & \text { fast discharge } \\ \text { ITER } & \text { International Thermonuclear Experimental Reactor } \\ \text { PV } & \text { plasma vessel } \\ \text { PSP } & \text { pumping gap panel } \\ \text { PDA } & \text { poloidal closure } \\ \text { SC } & \text { superconducting coil } \\ \text { TMv } & \text { vertical target module } \\ \text { TMh } & \text { horizontal target module } \\ \text { TDA } & \text { toroidal closure }\end{array}$

*E-mail: jiawu.zhu@ipp.mpg.de 


\section{INTRODUCTION}

The world's largest advanced stellarator Wendelstein 7-X (W7-X) has successfully passed the first operation phase with limited plasma configurations. Second phase commission- ing for the operation with an inertially cooled divertor is on the way. The W7-X consists of 5 quasi-identical modules, each of them includes two-flip symmetric half modules. Ten identical CVP (each for one half-module) are to be installed in W7-X together with other actively cooled in-vessel components before OP 2 [1]. Each CVP is situated in one divertor volume formed by graphite shielded baffle modules and divertor closures [2]. Fig. 1 shows the CAD model of one CVP inside the divertor volume and the adjacent in-vessel components.

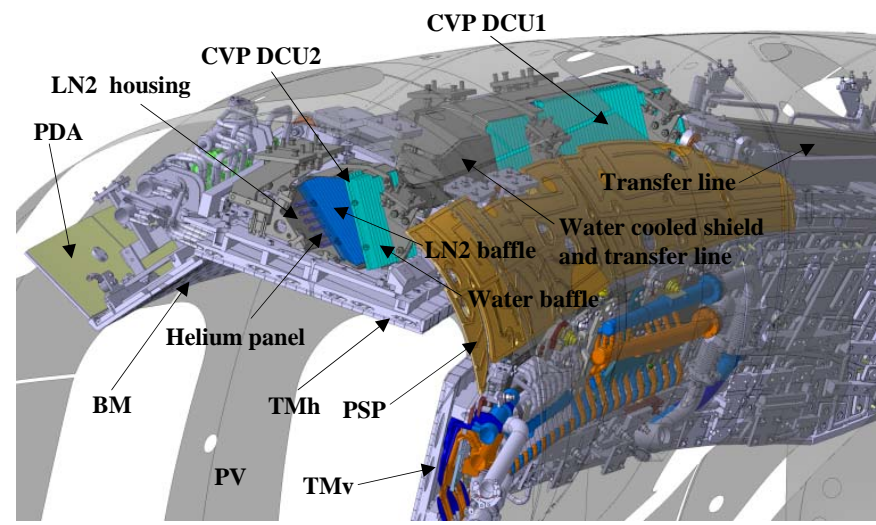

Fig. 1. View of CVP in divertor volume and the adjacent in-vessel components.

$\mathrm{PV}$ - plasma vessel, BM - baffle modules, TMh - horizontal target module, TMv - vertical target module, PSP - Pumping gap panel, PDA poloidal closure.

Each CVP includes two sections, named DCU1 and DCU2 (DCU: Divertor Cryopump Unit), both of them typically consists of water baffle, LN2 baffle, helium panel and LN2 housing cooled by water, LN2 and supercritical helium (ScHe). Besides, LN2 and helium cooling circuits of DCU1 and DCU2 are connected in series through transfer lines, as well as the connection between DCU1 and vacuum vessel feed through. Helium panel is surrounded and thermally protected by LN2 housing, LN2 baffle, etc., in order to maintain its temperature at about $4 \mathrm{~K}$ during plasma operation, which is crucial for achieving the absorption goal.

Thermal performance and cooling configuration of CVP are essential for its functionality. During W7-X plasma operation, part of ECRH (electron-cyclotron resonance heating) power will penetrate into divertor volume through the pumping gap, especially for the volumes of module 1 and 5, which are close to ECRH sources. As a result, most metal surfaces of CVP are exposed to ECRH power and heated up due to the absorption rates of about $1 \%, 0.2 \%, 2 \%$ and $70 \%$ for stainless steel (SS), copper $(\mathrm{Cu})$, LN2 chevron and water chevron respectively. High absorption rate of water baffle is achieved through $\mathrm{Al}_{2} \mathrm{O}_{3} / \mathrm{TiO}_{2}$ coating, which is developed to remove most of ECRH stray power by water cooling circuit in order to minimize the absorption on LN2 housing and helium panel. Stray ECRH power in divertor volume is varied from module to module as the followings: about $38 \mathrm{~kW} / \mathrm{m}^{2}$ for module 1 and $5,9 \mathrm{~kW} / \mathrm{m}^{2}$ for module 2 and 4 , and $2 \mathrm{~kW} / \mathrm{m}^{2}$ for module 3 . Therefore, it is necessary to optimize the cooling capacity distribution among the CVPs to meet different cooling requirements. Moreover, thermal radiation from the hot backside of the high loaded in-vessel components (such as baffle modules, divertor and toroidal closure) is significant for LN2 housing (see Table II). Furthermore, plasma radiation passing through the pumping gap and reaching to CVP is an additional heat source need to be considered in the thermal behavior study.

CVP EM performance is mainly focus on the eddy current induced in low resistance Cu components for the events of fast discharge of superconducting coils (SCs) current, plasma bootstrap current and trim coil current, and the alternating current (ac) in control coil. In particular, the large eddy current induced in PV shell during SCs and plasma current decay could partially divert into the attached CVP. As a result, due to the strong magnetic field generated by SCs, Lorenz forces following the vector product of $\mathbf{I} \times \mathbf{B}$ could be considerable and of great importance for CVP mechanical performance.

At first the article presents the complex 3D FE model, assumptions and procedures implemented for CVP thermal behavior analysis, the results of some scenarios with different boundary conditions (BC) / parameters for study, the discussion of some important issues and the LN2 and helium cooling configuration follow the results and studies. The second part is devoted to the procedure and results of CVP EM analysis, the estimation of currents entering CVP from PV, the resultant EM forces introduced in CVP. Finally, the mechanical performance of CVP is addressed (considering the loads of dead weight, temperature and EM forces) and is evaluated with the structural design criteria of in-vessel components and magnet system from ITER (International Thermonuclear Experimental Reactor). The paper presents refined multiphysics analysis of W7-X 
cryopumps in comparison with the work published in [3].

\section{THERMAL ANALYSIS}

A schematic view of the cross section of divertor chamber is shown in Fig. 2, which indicates the relative position of the in-vessel components (with the exception of invisible toroidal closure, TDA) and some CVP components. Each unit of CVP is mainly divided into four regions $(1 \sim 4)$ exposed to different ECRH power. ECRH power in whole divertor chamber (region 1 in Fig. 2) for different module is analyzed separately with specific ECRH power distribution model [4]. The ECRH power penetrates into region $2 \sim 4$ and power inside water cooling shield / transfer lines (not exposed directly to region 1) are estimated through energy balance with assumed absorption. Table I lists the ECRH power in different regions of divertor volume of each module and the power absorption of the components.

TABLE I

ECRH POWER AND ABSORPTION IN DIFFERENT REGIONS $\left(\mathrm{W} / \mathrm{m}^{2}\right)$

\begin{tabular}{|c|c|c|c|c|c|c|c|c|c|}
\hline \multicolumn{3}{|c|}{$\begin{array}{c}\text { Region } \\
\text { Module } \\
\end{array}$} & $1^{\mathrm{a}}$ & $2^{\mathrm{a}}$ & $3^{a}$ & $4^{\mathrm{a}}$ & $\begin{array}{l}\text { transfer } \\
\text { line } 1^{b}\end{array}$ & $\begin{array}{l}\text { transfer } \\
\text { line } 2^{\mathrm{c}}\end{array}$ & $\begin{array}{l}\text { transfer } \\
\text { line } 3^{\mathrm{d}}\end{array}$ \\
\hline \multirow{5}{*}{$\begin{array}{c}\text { MO1 } \\
\& \\
\text { MO5 }\end{array}$} & \multicolumn{2}{|c|}{$\begin{array}{c}\text { ECRH power } \\
\text { incident on surfaces }\end{array}$} & 38000 & 11400 & 11172 & 11060 & 11170 & 8400 & 7850 \\
\hline & \multirow{4}{*}{$\begin{array}{c}\text { Power } \\
\text { absorp- } \\
\text { tion }\end{array}$} & SS & 380.0 & 114.0 & 111.7 & 110.6 & 111.7 & 84.0 & 78.5 \\
\hline & & $\mathrm{Cu}$ & 76.0 & 22.8 & 22.3 & 22.1 & 22.3 & 16.8 & 15.7 \\
\hline & & $\begin{array}{c}\text { LN2 } \\
\text { chevron }\end{array}$ & \multicolumn{7}{|c|}{228} \\
\hline & & $\begin{array}{c}\text { Water } \\
\text { chevron }\end{array}$ & \multicolumn{7}{|c|}{26600} \\
\hline \multirow{5}{*}{$\begin{array}{c}\mathrm{MO} 2 \\
\& \\
\mathrm{MO} 4\end{array}$} & \multicolumn{2}{|c|}{$\begin{array}{c}\text { ECRH power } \\
\text { incident on surfaces }\end{array}$} & 9000 & 2700 & 2646 & 2619 & 2645.5 & 1989.5 & 1859.2 \\
\hline & \multirow{4}{*}{$\begin{array}{c}\text { Power } \\
\text { absorp- } \\
\text { tion }\end{array}$} & SS & 90.0 & 27.0 & 26.5 & 26.2 & 26.5 & 19.9 & 18.6 \\
\hline & & $\mathrm{Cu}$ & 18.0 & 5.4 & 5.3 & 5.2 & 5.3 & 4.0 & 3.7 \\
\hline & & $\begin{array}{c}\text { LN2 } \\
\text { chevron }\end{array}$ & \multicolumn{7}{|c|}{54.0} \\
\hline & & $\begin{array}{c}\text { Water } \\
\text { chevron }\end{array}$ & \multicolumn{7}{|c|}{6300} \\
\hline \multirow{5}{*}{$\mathrm{MO} 3$} & \multicolumn{2}{|c|}{$\begin{array}{c}\text { ECRH power } \\
\text { incident on surfaces }\end{array}$} & 2000 & 600 & 588 & 582.1 & 587.9 & 442.1 & 413.2 \\
\hline & & SS & 20.0 & 6.0 & 5.9 & 5.8 & 5.9 & 4.4 & 4.1 \\
\hline & Power & $\mathrm{Cu}$ & 4.0 & 1.2 & 1.2 & 1.2 & 1.2 & 0.9 & 0.8 \\
\hline & $\begin{array}{c}\text { absorp- } \\
\text { tion }\end{array}$ & $\begin{array}{c}\text { LN2 } \\
\text { chevron }\end{array}$ & \multicolumn{7}{|c|}{12} \\
\hline & & $\begin{array}{l}\text { Water } \\
\text { chevron }\end{array}$ & \multicolumn{7}{|c|}{1400} \\
\hline
\end{tabular}

${ }^{a}$ See Fig. 2

${ }^{b}$ Outer surfaces of transfer line between DCU1 and DCU2, and the inner surfaces of water shield between DCU1 and DCU2.

Inner surfaces of transfer line between DCU1 and DCU2.

${ }^{\mathrm{d}}$ Inner surfaces of transfer line connected with vacuum vessel feed through.

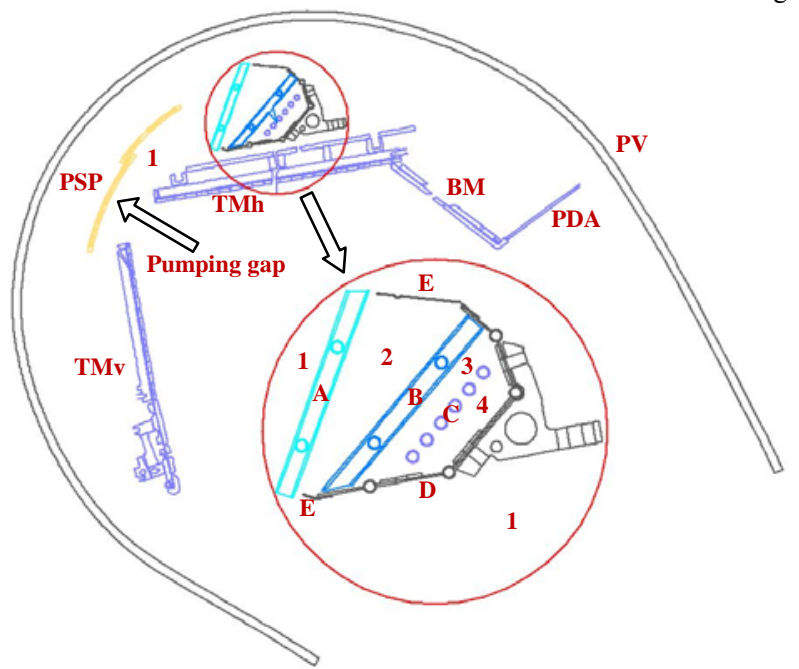

Fig. 2. Schematic view of the divertor chamber cross section (CVP is in red circle). A - water chevrons (Cu, water cooled), B - LN2 chevrons (SS, LN2 cooled), C - helium panel (SS, ScHe cooled), D - LN2 housing (LN2 cooled), E - Copper cover (to prevent ECRH power penetrated into CVP through the gap between A and B, floating), 1 - ECRH load in whole divertor chamber, 2 - ECRH load in front of LN2 baffle taking into account the absorption of the water baffle, 3 - ECRH load behind the LN2 baffle, 4 - ECRH load behind the helium panel. 
As mentioned above, the heat radiation from the backside of high loaded in-vessel components is to be included in the thermal analysis. Due to the sophisticated structure and cooling scheme, a set of simplified model of PV and in-vessel components is adopted and specified with effective temperature and emissivity, which are calculated / estimated for different studied cases (some typical cases are selected and listed in Table II). Backside protection (BS) is the additional plates which may be installed at the backside area of high loaded TDA and BM to protect the components behind the in-vessel components. The temperature of BS is estimated to be the same as $\mathrm{CuCrZr}$ elements according to the experiment reported in [5]. Shading effect due to multiple cooling pipes for in-vessel components in the divertor chamber is considered in some analysis cases (TH3 TH6) by deducting the shaded radiation power in percentage. Plasma radiation is also considered in cases (TH5 and TH6) by introduction of an artificial plate closing the pumping gap, the plate temperature is adjusted for emitting the same radiation power (substituted by corresponding thermal radiation). In addition, for all studied cases, PV temperature is set to $60{ }^{\circ} \mathrm{C}$ which is estimated due to low ECRH power incident on inner surfaces and active water cooling, and the environment temperature is set to $150^{\circ} \mathrm{C}$ due to the entire model is not fully enclosed and the open areas are mostly facing to the in-vessel components.

\section{A. FE model and Boundary conditions}

Due to the fact that CVPs are located in the same position of each W7-X half module, FE model of only one CVP in half module 1 of first module is created, as well as the adjacent in-vessel components. As indicated in Fig. 3, FE model of CVP is enclosed by the simplified divertor chamber model formed by PV, TDA, PSP, TM, etc. Some of unimportant features of CVP, such as bolts and holes, are skipped for simplification. Nevertheless, there are about 3.8 million nodes and 1.2 million finite elements in the model. Effective temperature of PV and in-vessel components (listed in Table II) is applied on their inner surfaces as boundary conditions. Temperature and convection coefficient of the coolants (calculated by considering as one phase flow) are assumed to be constant:

$$
\begin{aligned}
& \text { Water: } \quad 50^{\circ} \mathrm{C} \& 33 \mathrm{~kW} / \mathrm{m}^{2} \cdot \mathrm{K} \\
& \text { LN2: } \quad 80 \mathrm{~K} \& 448.3 \mathrm{~W} / \mathrm{m}^{2} \cdot \mathrm{K} \\
& \text { Helium: } \quad 4 \mathrm{~K} \& 2400 \mathrm{~W} / \mathrm{m}^{2} \cdot \mathrm{K}
\end{aligned}
$$

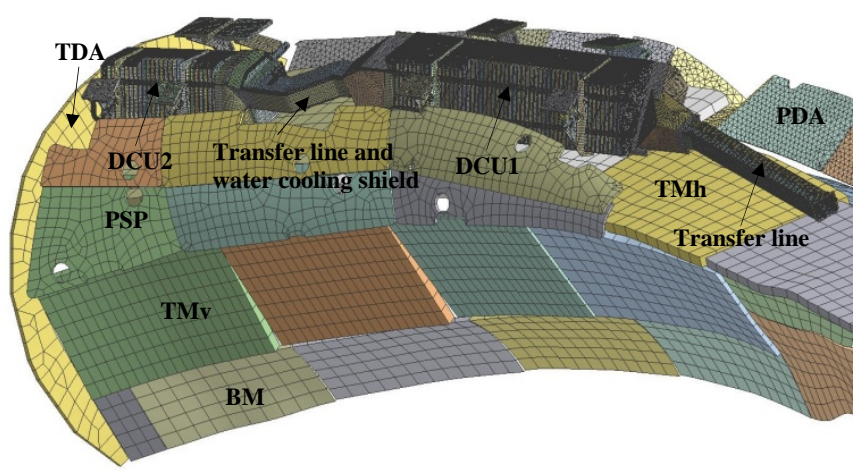

Fig. 3. FE model for CVP thermal analysis (FE model of PV is hidden).

All the material properties are set as temperature dependent, and the thermal conductivity of helium panel (SS) at $4 \mathrm{~K}$ is $0.273 \mathrm{~W} / \mathrm{m} \cdot \mathrm{K}$. Heat flux calculated according to the absorption rate and the ECRH power in different region is applied on specific surfaces. Heat radiation is considered through creating corresponding radiation enclosures, in which radiation heat is reflected / absorbed. In addition, the frictional heating in the cooling pipes are assumed to be marginal and skipped in calculation. 
TABLE II

TEMPERATURE $\left({ }^{\circ} \mathrm{C}\right)$ AND EMISSIVITY OF SELECTED CASES

\begin{tabular}{c|cccccc}
\hline \hline Cases & TH1 & TH2 & TH3 & TH4 & TH5 & TH6 \\
\cline { 2 - 7 } BS $^{\mathrm{a}}$ & without & with & with & with & with & with \\
SE $^{\mathrm{b}}$ & $0 \%$ & $0 \%$ & $25 \%$ & $50 \%$ & $25 \%$ & $25 \%$ \\
PR $^{\mathrm{c}}$ & 0 & 0 & 0 & 0 & 100 & 50 \\
PV & & \multicolumn{7}{c}{$60,0.5^{\mathrm{d}}$} & & \\
BM & $669,0.44$ & $362,0.2$ & $318,0.2$ & $260,0.2$ & $318,0.2$ & $318,0.2$ \\
TDA & $669,0.44^{\mathrm{g}}$ & $362,0.2$ & $318,0.2$ & $260,0.2$ & $318,0.2$ & $318,0.2$ \\
TM 1-4h & $177,0.47$ & $177,0.47$ & $146,0.47$ & $105,0.47$ & $146,0.47$ & $146,0.47$ \\
TM 5-6h & $450,0.2$ & $450,0.2$ & $399,0.2$ & $334,0.2$ & $399,0.2$ & $399,0.2$ \\
PSP & \multicolumn{7}{c}{$150,0.5$} & & \\
PDA & \multicolumn{7}{c}{$60,0.5$} & & \\
\hline \hline
\end{tabular}

${ }^{\mathrm{a}}$ Backside protection.

${ }^{\mathrm{b}}$ Shading effect.

${ }^{\mathrm{c}}$ Plasma radiation, $\mathrm{kW} / \mathrm{m}^{2}$.

${ }^{\mathrm{d}}$ Temperature and emissivity in respective.

${ }^{\mathrm{e}}$ No. 1-4 of horizontal target modules.

${ }^{f}$ No. 5-6 of horizontal target modules.

${ }^{\mathrm{g}}$ High temperature of BM and TDA backside area is result from high temperature and emissivity of graphite and no actively cooled backside protection.

\section{B. Main Results}

In order to save computational resources and run time, static thermal analysis has been performed for most of the cases with ANSYS ${ }^{\circledR}$ Workbench. Heat loads of water, LN2 and helium cooling circuits are listed in Table III for the selected cases (TH1 TH6) corresponding to different modules, some of them are estimated according to the approximately linear dependence on ECRH load. As indicated in Table III, both the backside protection and the shielding effect have marginal direct influence on heat load on water and helium circuits, while decrease the heat load on LN2 cooling circuit significantly due to the reduction of some in-vessel components temperature facing LN2 cooled components. In case of introduction of $100 \mathrm{~kW} / \mathrm{m}^{2}$ plasma radiation (case TH5), heat load on water and LN2 cooling circuits increases by about $1.2 \mathrm{~kW}$ and $220 \mathrm{~W}$ respectively for each CVP in different module, while the effect is marginal for helium cooling circuit. Fig. 4 and Fig. 5 show the temperature distributions in CVP and the helium cooling pipes for case TH3. Due to the high ECRH absorption rate of water chevron surfaces, both the temperature at the edge of chevrons and the temperature gradient along the chevron are quite high. Temperature of LN2 housing (except the cooling pipes) is well above the cooling temperature of $80 \mathrm{~K}$ due to heat radiation and ECRH load. Part of the thermal radiation is due to overheated water chevrons as mentioned above. Temperature of most helium cooling pipes surfaces is lower than $4.6 \mathrm{~K}$ with the exception of the areas attached to supports.

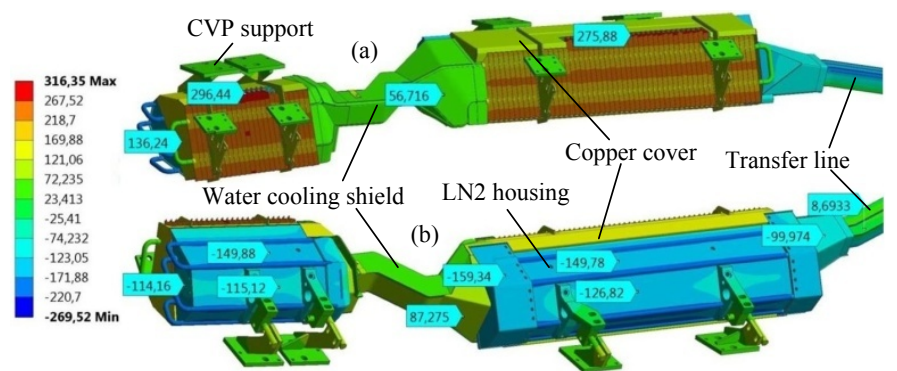

Fig. 4. Temperature distribution of CVP (case TH3, unit ${ }^{\circ} \mathrm{C}$ ), (a). Temperature of water baffle, (b). Temperature of LN2 housing. 
TABLE III

HeAt REMOVED By WATER, LN2 AND Helium (W)

\begin{tabular}{c|cccc}
\hline \hline \multirow{2}{*}{ Cases } & MO1 \& 5 & MO2 \& 4 & MO3 & Total \\
\cline { 2 - 5 } TH1 & $4 \times(32250$, & $4 \times(7775$, & $2 \times(1697$, & $(163494$, \\
& $2695,65)$ & $1305,18.6)^{\mathrm{a}}$ & $1072,7.8)$ & $18144,350)$ \\
TH2 & $4 \times(31869$, & $4 \times(7664$, & $2 \times(1673$, & $(161478$, \\
& $1885,62)$ & $913,16)$ & $750,6.7)$ & $12692,325)$ \\
TH3 & $4 \times(31810$, & $4 \times(7650$, & $2 \times(1670$, & $(161180$, \\
& $1758,60)$ & $852,15.5)$ & $700,6.5)$ & $11840,315)$ \\
TH4 & $4 \times(31745$, & $4 \times(7635$, & $2 \times(1667$, & $(160854$, \\
& $1613,58)$ & $790,15)$ & $649,6.3)$ & $10910,305)$ \\
TH5 & $4 \times(33024$, & $4 \times(8864$, & $2 \times(2884$, & $(173320$, \\
& $1979,61)$ & $1073,16.5)$ & $921,7.5)$ & $14050,325)$ \\
& $4 \times(32430$, & $4 \times(8270$, & $2 \times(2290$, & $(167380$, \\
TH6 & $1878,61)$ & $972,16.5)$ & $820,7.5)$ & $13040,325)$ \\
\hline \hline
\end{tabular}

${ }^{\mathrm{a}}$ Values in red color are the estimations.

${ }^{\mathrm{b}}$ Reference case for mechanical analysis.

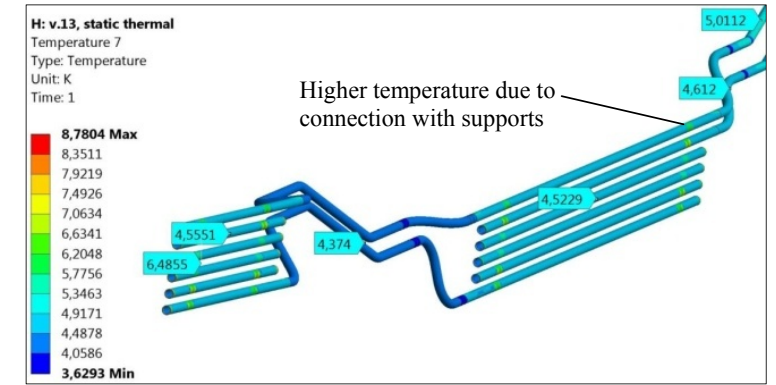

Fig. 5. Temperature distribution of helium panel (case TH3, unit K).

\section{Important issues}

As indicated in Table III, the prediction of LN2 circuit heat load is quite sensitive to the temperature and emissivity of in-vessel components due to the large proportion of heat radiation load, as a result, the accuracy of LN2 level heat load depends on the accuracy of estimations on in-vessel components. However, considering the influences from shielding effect and plasma radiation, the predictions of case TH3 (selected as a reference case) should be reasonable and close to the reality due to the lower shielding effect (25\%) using in calculation, which could compensate the plasma radiation to some extent.

Due to the constant coolant temperature and convection coefficient specified in the model, the accuracy of presented temperature distribution and heat loads depends on the hydraulic parameters implemented in the project.

The port plug LN2 and helium feed lines are not included in the FE thermal model, therefore, heat loads on these parts are not considered. However, according to the analysis results presented in [6], heat loads on these parts are negligible.

The copper cover closing the gap between the water baffle and the LN2 baffle (see Fig. 2 and Fig. 4) could introduce an additional heat load on LN2 level through thermal conduction if it is thermally attached to LN2 housing (not the case in presented analysis). Therefore it is recommended that some small spacers between copper cover and LN2 housing are to be introduced during manufacturing processes.

The evaporation of carbon from graphite tile surfaces of in-vessel components and their re-deposition on other in-vessel component and cryopump outer surfaces during plasma operation [7] could increases their emissivities. To investigate such emissivity degradation on the cryopump thermal performance, an additional thermal analysis has been performed with the emissivities of in-vessel components and cryopump outer surfaces increased from $0.2 \sim 0.5$ to 0.7 . The results indicate a heat load increase of about $28 \%$ and $30 \%$ on $\mathrm{ScHe}$ and nitrogen cooling circuits respectively. However, probability of such degradation is low due to the following reasons:

1). Carbon re-deposition is significantly reduced in W7-X due to well alignment of the tiles (strict control of steps/gaps between neighboring tiles and modules during installation). The JT60 experience summarized in [7] highlights the issue as the most influencing one.

2). According to the preliminary observations in OP1.2a, plasma ECRH absorption rate is high and stray ECRH power on in-vessel components is lower than it was assumed originally. Therefore, the ECRH power specified in cryopump thermal analysis is overestimated and gives some margin to cover carbon re-deposition 
effect.

3). In accordance with the statement in study [8], stable carbon layer is not expected in shadow areas; therefore proposed 0.7 surface emissivity is reasonably conservative.

4). Further modifications of cryo system are possible to improve nitrogen cooling.

In addition, transient thermal behavior of CVP has been performed for some cases to estimate a characteristic thermal time of CVP within the designed 30 minutes long plasma operation pulse of W7-X. The results show that it takes about 17 minutes to reach the static thermal state. Therefore, it is reasonable to configure the cooling capacity according to the static thermal analysis results.

\section{LN2 and Helium Cooling Concept}

The major task of the CVP is the pumping of hydrogen (H2) and deuterium (D2) to control the gas density and as a result the plasma density. As the helium panels have originally no coating like charcoal, the minimum chamber pressure is defined by the vapor pressure of the adsorbed gases. At $4.4 \mathrm{~K}$ the vapor pressures of hydrogen (H2) and deuterium (D2) are $2.4 \times 10^{-6}$ mbar and $8 \times 10^{-10}$ mbar respectively. As a rule of thumb the minimum achievable end pressure is a $1 / 10$ of the chamber pressure. Ideal pumping speed requires a saturation pressure at the cold surface of $1 / 100$ of the chamber pressure [9]. Helium panel temperatures of $4.4 \mathrm{~K}$ allow a minimum chamber pressure of $2.4 \times 10^{-5}$ mbar for $\mathrm{H} 2$ and $8 \times 10^{-9}$ mbar for D2. Ideal pumping speed is possible for chamber pressures at $2 \times 10^{-4} \mathrm{mbar}$ for $\mathrm{H} 2$. Pumping of helium is possible with argon frosting only.

The helium panels are supplied with supercritical helium at $3.9 \mathrm{~K}$ (at the outlet of the valve box). The available cooling power from the cryo plant is $450 \mathrm{~W}$ for the helium panels of the CVP-cooling. Calculated heat loads of $350 \mathrm{~W}$ (see Table III) fit therefore well to the cryo plant design value. An inlet temperature of $3.9 \mathrm{~K}$ results in an outlet temperature of $4.4 \mathrm{~K}$.

The nitrogen cooling circuits take a heat load up to about $12 \mathrm{~kW}$. Two cooling options will be realized. Option 1 uses liquid nitrogen that will be evaporated up to a vapor fraction of $90 \%$ with a mass flow rate of $70 \mathrm{~g} / \mathrm{s}$. The liquid nitrogen is taken from a LN2-tank with a capacity of $30 \mathrm{~m}^{3}$ and flows through a heat exchanger that is placed inside a LN2-bath at 1.2 bar. The evaporated nitrogen from the return flow of the CVPs is collected and returned to the phase separator of the helium refrigerator. Higher thermal loads than $12 \mathrm{~kW}$ increases the risk of overloading the phase separator. The energy of the nitrogen flow is used for the cooling process in the cold box of the cryo plant. Option 2 is based on sub cooled nitrogen that is pushed through the cooling circuits with a cold pump. A flow of $600 \mathrm{~g} / \mathrm{s}$ sub cooled nitrogen is needed when a temperature rise of $10 \mathrm{~K}$ is allowed.

\section{E. LN2 and Helium Piping Concept}

A transfer line with a length of about $50 \mathrm{~m}$ connects the helium refrigerator with the dedicated valve box for the CVP. The box is located in the second basement of the torus hall below the W7-X cryostat. It is connected with 10 transfer lines that consist of four process pipes each, two for helium and two for nitrogen supply (feed and return). The ten transfer lines connect the valve box with 10 ports of the cryostat. The pipes run through ports into the plasma vessel and are finally connected with the CVP. First DCU1 and then DCU2 are cooled.

The length of the transfer line between box and ports is $10 \mathrm{~m}$ and $16 \mathrm{~m}$ respectively, depending on the location of the CVP for each module. Hydraulically, the two CVP of a module are connected in series for the nitrogen cooling and connected in parallel for the He-cooling. Series cooling for a CVP ensures the same pressure drop for the cooling circuits and reduces the number of valves in the crowded valve box. The increased heat loads in the modules 5 and 1 (see first result column in Table III) require a parallel cooling scheme for the LN2 cooling. As a result, both the LN2 cooling and the helium cooling are connected in parallel, which allows a higher mass flow rate for a given pressure drop. Pressure drop and mass flow for the helium cooling is limited by the cold helium circulator of the cryo plant (600 mbar at $250 \mathrm{~g} / \mathrm{s})$. Since the helium flow rate of each CVP is controlled independently, a mass flow rate higher than $25 \mathrm{~g} / \mathrm{s}$ per CVP could be supplied for the CVP in module 1 and 5 (due to higher heat load) and lead to a temperature rise of about $0.5 \mathrm{~K}$.

The pressure drop along the flow path from the valve box to the CVP and return is 265 mbar for the Hecooling. The pressure drop for the LN2-cooling is 1.9 bar for the series cooling scheme with $11.6 \mathrm{~g} / \mathrm{s}$ (required flow for $1 \mathrm{~kW}$ per CVP). For simplification of the calculation the nitrogen was considered as a gas. For the parallel cooling scheme the pressure drop is 1.1 bar for $2 \mathrm{~kW}(11.6 \mathrm{~g} / \mathrm{s})$. As a result of the pressure drop the evaporation temperature varies between $90 \mathrm{~K}$ at the inlet and $80 \mathrm{~K}$ at the outlet.

The mass flow measurements and control valves are planned for the single cooling circuits. Temperature sensors at inlet and outlet allow the calculation of the heat loads for single phase cooling conditions.

The cooling concept provides a cooling of the helium panels in the temperature range from $3.9 \mathrm{~K}$ to $4.4 \mathrm{~K}$. The installed cooling power for the helium circuits is sufficient. The pressure drops for the nitrogen circuits are below 2 bars and ensure cooling temperatures range of 80-90 K. 


\section{ELECTROMAGNETIC ANALYSIS}

The optimized field configurations in W7-X are generated / adjusted by the sophisticated magnet system comprising 70 superconducting coils (SCs), 10 control coils and 5 trim coils. The superconducting coils are toroidally arranged in five equal modules and categorized as seven types [10-11]. Each type of SC including ten identical coils that connected in series and fed by single power supply. Ten identical control coils are wound from copper conductors and periodically located inside of PV and behind the baffle modules to avoid the symmetry breaking error field and to sweep high peak plasma depositions across the target plates [12]. Five trim coils (normal conducting) are placed outside of W7-X cryostat providing an approach to balance the divertor heat loads and correct the error fields [13]. The trim coils are periodically arranged around the W7-X, but with two different types which break the cyclic symmetry. Due to the EM coupling between CVP and these coils, eddy currents could be induced in CVP when altering the coil currents. The plasma bootstrap current could be treated as a special coil following the plasma axis with an approach similar to other coils. In order to evaluate the eddy currents and the resulted Lorentz forces in a conservative way and to simplify the EM model, the following assumptions are adopted for EM analysis:

1). SS components of CVP are omitted due to high resistivity (about $8.0 \times 10^{-7} \Omega \cdot \mathrm{m}$ ), only Cu components of CVP (see Fig. 7) are taken in the EM analyses. Relatively low resistivity of $\mathrm{Cu}\left(1.7 \times 10^{-8} \Omega \cdot \mathrm{m}\right)$ is taken in calculation to be conservative.

2). Plasma operation regime 'Low Shear' with target 3T magnetic induction on the plasma axis is taken as a starting point of the fast discharge of SCs current. Linear current decayed to zero in 3 seconds (time constant) is assumed in each type of SC simultaneously.

3). Plasma current is modeled as a 'distorted cylinder' (cross section diameter is specified as $0.4 \mathrm{~m}$ ) following the plasma axis, see Fig. 6.

4). Asymmetry of trim coils is ignored, and type B trim coil is taken in the $72^{\circ}$ EM model due to its higher current and higher current discharge rate.

5). All the coils are modeled in simplified way that neglects the real structure of conductors and insulations. An average current density is applied to the cross-section of the winding pack.

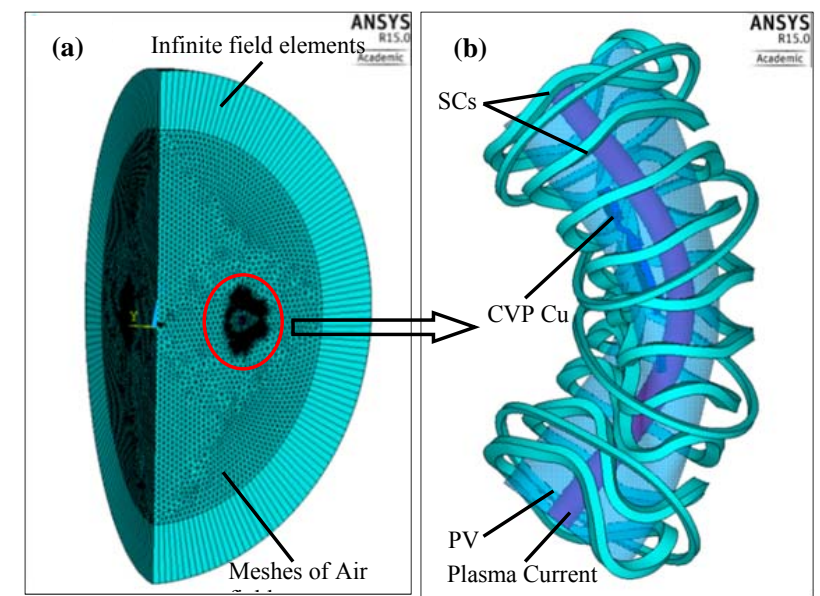

Fig. 6. EM model for CVP eddy current analysis. (a) Overall view of $72^{\circ} \mathrm{EM}$ model; (b) Model of SCs, plasma current, PV and CVP (top view). 


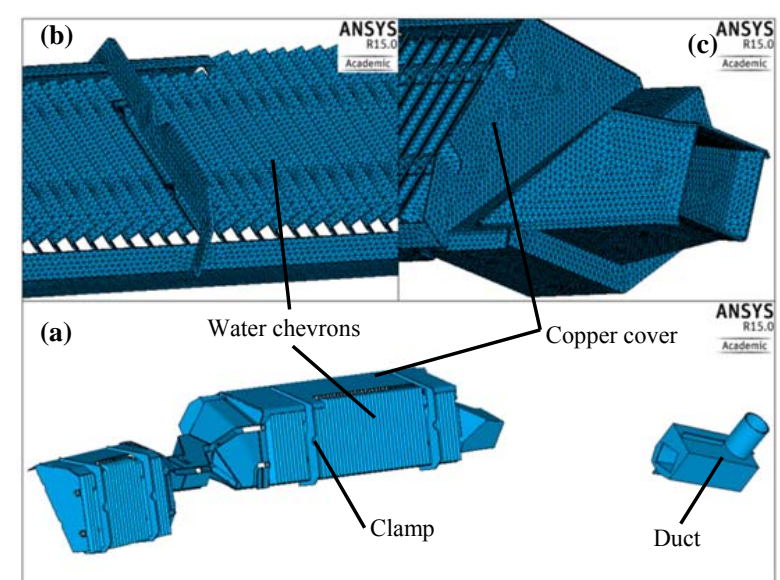

Fig. 7. FE model of CVP Cu components in EM model. (a) Overall view of the CVP Cu components; (b) mesh of water chevrons; (c) mesh of DCU1 end Cu components.

The EM analysis of CVP is performed in ANSYS ${ }^{\circledR}$ 15.0. Fig. 6 shows the $72^{\circ} \mathrm{EM}$ model (with cyclic boundary condition) for the cases of SCs current FD and FD of plasma current. The PV shell (SS, thickness of $17 \mathrm{~mm}$ ) is also included to take the shielding effect into account, while the connected ports are excluded for simplification. The air field radius is $10 \mathrm{~m}$, while infinite field elements length is $3 \mathrm{~m}$. This FE model is with about 1.1 million nodes and 6.7 million elements in total. Fig. 7 shows the details of CVP Cu components in the FE model.

An additional EM model is created for the case of trim coil FD and ac in control coil, as shown in Fig. 8. The air mesh is similar to the one in Fig. 6, but the radius of air field is increased to $12 \mathrm{~m}$. About 0.8 million nodes and 4.7 million elements in total are generated for this model.

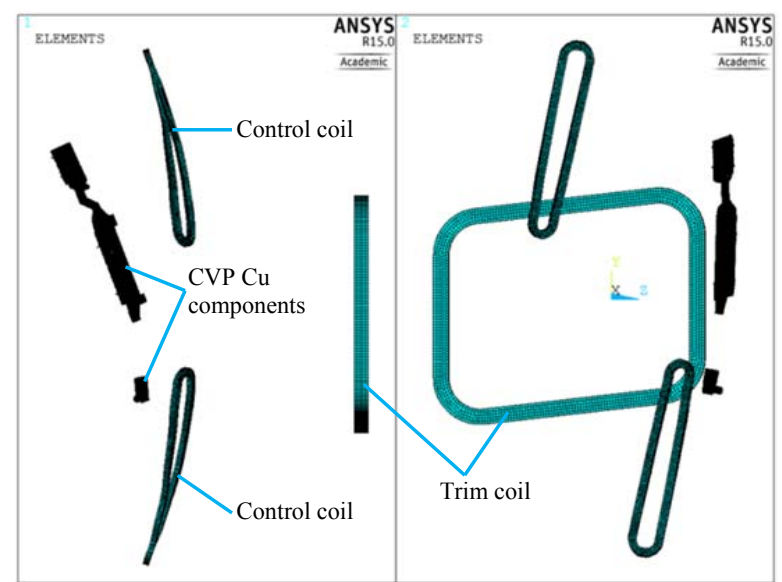

Fig. 8. EM model for CVP eddy current analysis, for the case of FD of trim coil (Type B) and alternating current in control coil.

\section{A. Fast Discharges of SC and plasma currents}

Fig. 10 and Fig. 11 show the current decay curves of SCs (case EM1) and plasma current (case EM2) respectively, as implemented in the CVP transient EM analysis. For case EM1, all the SC currents are linearly decayed simultaneously from steady state to zero in 3 seconds (time constant). At the start point (time 0 ), the transient effect is turned off to model static behavior at the beginning. For case EM2, the plasma current is decayed exponentially with a smaller time constant of $140 \mathrm{~ms}$, while the SCs currents are kept constant to take the field from SCs into account for forces calculation.

The eddy current density (in vectors) in the DCU1 end $\mathrm{Cu}$ component is shown in Fig. 9 as an example. Due to the dominated toroidal field generated by SCs, the eddy current is mainly in poloidal direction. In order to make the results more intuitive and visible, as illustrated in Fig. 9, several paths are defined in some of the $\mathrm{Cu}$ components to integrate the current through the cross section along the path. For instances, Fig. 10 and Fig. 11 show the integrated eddy current versus time for case EM1 and EM2 respectively. Obviously, the eddy current is almost constant in the current decay period for case EM1 due to the constant current discharge rate (linear decay), while the eddy current for case EM2 changes rapidly at the beginning of current decay. 


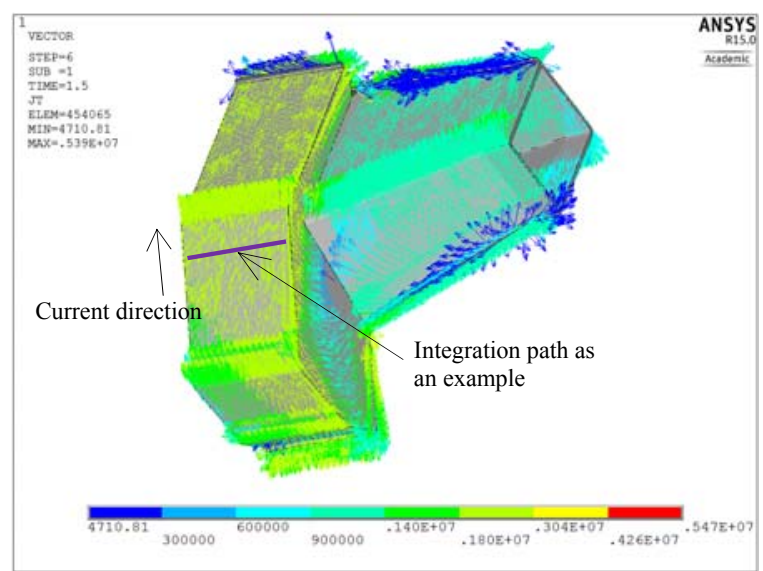

Fig. 9. Eddy current density vector in DCU1 end Cu component (case EM1), A/ $\mathrm{m}^{2}$.

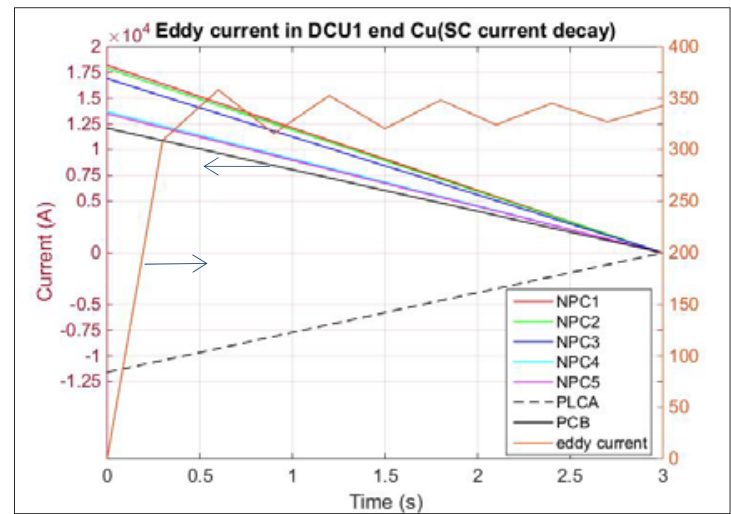

Fig. 10. Current decay curves of SCs (A/turn of each SC) and the integrated eddy current in DCU1 end Cu component versus time.

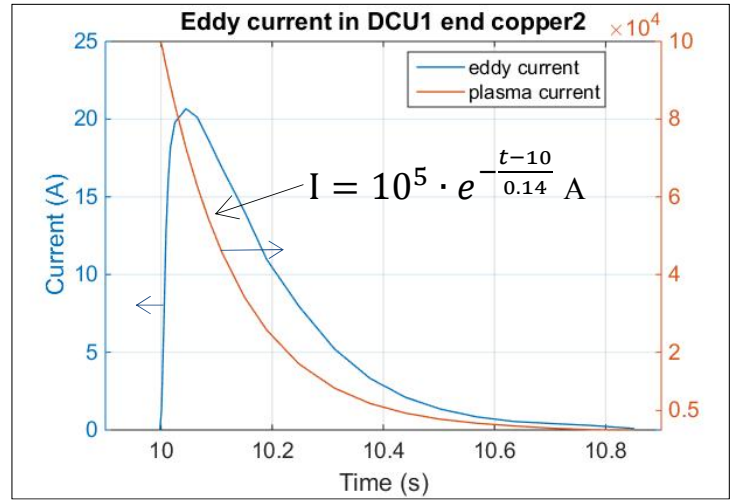

Fig. 11. Plasma current decay curve and the integrated eddy current versus time.

TABLE IV

EDDY CURRENTS IN CU COMPONENTS (A)

\begin{tabular}{|c|c|c|c|c|c|c|c|}
\hline Cases & $\begin{array}{l}\text { DCU1 } \\
\text { chevron }\end{array}$ & $\begin{array}{l}\text { DCU2 } \\
\text { chevron }\end{array}$ & $\begin{array}{c}\text { DCU1 } \\
\text { end Cu } \\
\text { (left) }\end{array}$ & $\begin{array}{l}\text { DCU1 } \\
\text { end Cu } \\
\text { (right) }\end{array}$ & Duct & $\begin{array}{l}\text { Copper } \\
\text { cover }\end{array}$ & $\begin{array}{c}\text { Water } \\
\text { cooling } \\
\text { shield } \\
\mathrm{Cu} \\
\end{array}$ \\
\hline${ }^{\mathrm{a}} \mathrm{EM} 1-\mathrm{a}$ & 11.37 & 11.48 & 362.4 & 334.4 & 551.8 & 25.5 & 29.2 \\
\hline${ }^{\mathrm{b}} \mathrm{EM} 1-\mathrm{b}$ & 11.4 & 11.5 & 363.4 & 335.3 & 553.3 & 25.5 & 29.2 \\
\hline${ }^{c}$ EM2-a & 0.258 & 0.067 & 24.6 & 20.7 & 44.3 & 10.0 & 7.1 \\
\hline${ }^{\mathrm{d}} \mathrm{EM} 2-\mathrm{b}$ & 0.40 & 0.02 & 29.6 & 28.8 & 61.6 & 14.3 & 8.2 \\
\hline
\end{tabular}

The eddy currents in some of the $\mathrm{Cu}$ components for different calculation cases are listed in Table IV for comparison. Due to relatively higher flux density change rate in CVP during FD of SCs current (about $0.8 \sim$ $1.16 \mathrm{~T} / \mathrm{s}$ ) in comparison with the one of FD of plasma current (less than $0.17 \mathrm{~T} / \mathrm{s}$ ), the eddy current in EM1 case is much higher than case EM2. Maximum eddy current of about $550 \mathrm{~A}$ is induced in the duct. For benchmarking purpose, the eddy current in DCU1 water chevron is also estimated for case EM1 by hand using normal flux 
density and mutual inductance, the formulas are following:

$$
\mathrm{U}=-\mathrm{dB} \perp \cdot \mathrm{A} / \mathrm{dt}, \mathrm{I}=\mathrm{U} / \mathrm{R}
$$

$\mathrm{U}$ - Induced voltage, $\mathrm{B} \perp$ - Flux density normal to the chevron plane, $\mathrm{A}-$ Area of the chevron current loop, $\mathrm{R}-$ Resistance of chevron.

$$
\frac{d i_{2}}{d t}=\frac{M_{12}}{L_{2}} \frac{d i_{1}}{d t}-\frac{R_{2}}{L_{2}} i_{2}
$$

$\mathrm{i}_{2}-$ current in chevron, $\mathrm{i}_{1}-$ current in coils, $\mathrm{M}_{12}-$ mutual inductance, $\mathrm{R}_{2}-$ resistance of chevron, $\mathrm{L}_{2}-$ selfinductance of chevron.

The estimations result in the current values of about $9.92 \mathrm{~A}$ and $11.2 \mathrm{~A}$ respectively, which are close to the results in Table IV. In addition, the shielding effect of PV is assessed by comparing the cases with and without PV (see values in Table IV), about $0.3 \%$ for case EM1 and 30\% for case EM2. Lower shielding effect of case EM1 results from the longer time constant of SCs current decay in comparison with plasma current decay.

\section{B. Fast discharge of trim coil current and ac in control coil}

Current decay of trim coil and the alternating current (ac) in control coil (case EM3), together with the eddy current in duct are shown in Fig. 12. Due to the fact that one of the ducts is close to the control coil (see Fig. 8), the current density in the duct is higher than in other $\mathrm{Cu}$ components and the largest eddy current in duct could reach up to about $59 \mathrm{~A}$ at time $0.03 \mathrm{~s}$ and $0.08 \mathrm{~s}$ (see Fig. 12).

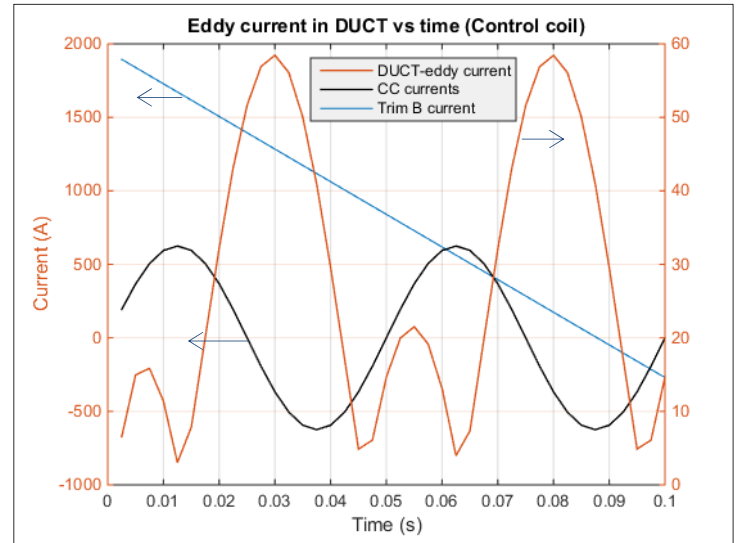

Fig. 12. Current decay of trim coil (discharge rate $22.2 \mathrm{kA} / \mathrm{s}$ per turn) and ac in control coil ( 8 turns $\times 625 \mathrm{~A}, 20 \mathrm{~Hz}$ ), and the induced eddy current in $\operatorname{duct}(\mathrm{A})$

\section{Current sharing between PV and CVP}

Part of the eddy current in the PV during FD of SCs current and plasma current enters the CVP due to the attachment of CVP supports to the PV. In order to estimate the shared currents in the CVP, considering the dominated eddy current direction in the PV (in poloidal for case EM1, and in toroidal for case EM2), the FE model of the CVP (without the model of in-vessel components) created for thermal analysis is utilized and attached to the FE model of a piece of the PV (shown in Fig. 13). The electrical analysis (cases ET1 and ET2) is performed with this FE model by applying the current in one of the PV edge cross section, and grounding the opposite edge cross section. The specified current is calculated according to the eddy current density in the PV local area attached to the CVP from the calculated cases 'EM1-a' or 'EM2-a'.

Fig. 14 shows the current density in the CVP due to dominated poloidal eddy current (FD of SCs current) in the PV. The shared current in total is about 120 A during FD of plasma current (case ET2), and about 70 A during FD of SCs current (ET1). The lower current sharing of case ET1 is due to the detachment between copper cover and LN2 housing, which breaks the current conduction between the supports with high and low voltages. Therefore, detachment of copper cover and LN2 housing is an advantage not only for thermal performance but also for EM performance.

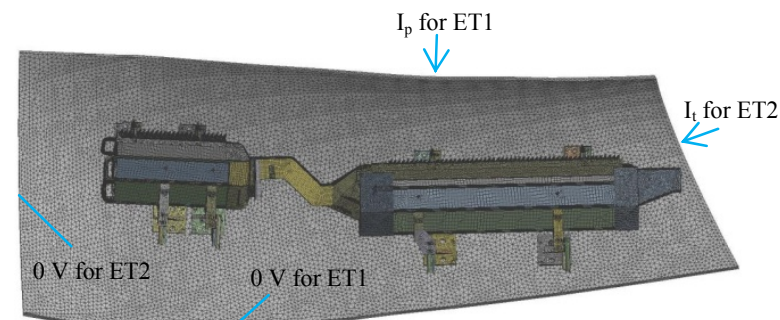

Fig. 13. FE model and boundary conditions for electrical analysis, case ET1 - poloidal current $\mathrm{I}_{\mathrm{p}}$ (current density about $450 \mathrm{kA} / \mathrm{m}^{2}$, during FD of SC current), case ET2 - toroidal current $\mathrm{I}_{\mathrm{t}}$ (current density about $145 \mathrm{kA} / \mathrm{m}^{2}$, during FD of plasma current). 


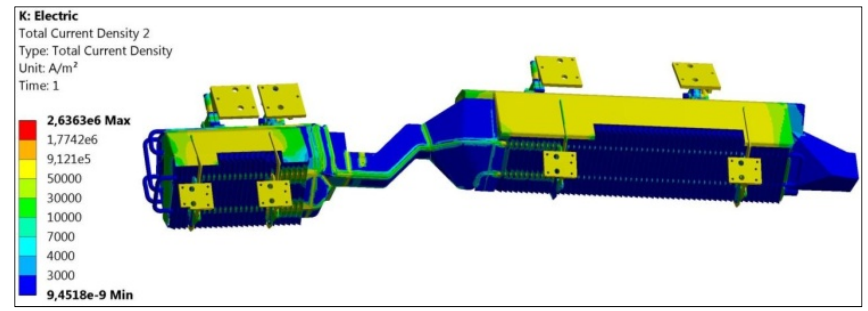

Fig. 14. Current density in CVP for case ET1, A/m².

\section{Lorentz forces in CVP}

The Lorentz forces are of great importance for CVP structural analysis. The force densities in $\mathrm{Cu}$ could be directly derived from EM analysis results of cases EM1 and EM2. However, for cases EM3, ET1 and ET2, the flux density from SCs is not included in the analysis, therefore, an additional routine has been created in MATLAB $^{\circledR}$ to calculate the force densities through $\mathbf{J} \times \mathbf{B}$. Fig. 15 shows the force density distribution in $\mathrm{Cu}$ components during FD of SCs current with the consideration of current sharing with PV. The DCU1 end Cu components are with relatively high EM forces. Forces in clamps are increased to some extent when the current sharing is considered. Lorentz force densities in CVP SS components due to current sharing with PV, as shown in Fig. 16, are also calculated with the approach described above. The highest forces are located in supports, while forces in other parts are marginal comparing with the forces in $\mathrm{Cu}$ components.

EM forces in main $\mathrm{Cu}$ components are summed and collected in Table $\mathrm{V}$ for comparison. The maximum force is less than $17 \mathrm{~N}$ due to the fact that forces in opposite directions are neutralized. EM forces in case EM2-a are about 10 times lower than in case EM1-a, as a result, they are not considered for mechanical analysis. Furthermore, it is logically impossible to have case 'EM1-a' and ET2 simultaneously. Therefore, the combined case of "EM1-a \& ET1" and case EM3 are selected as a worst scenario for the mechanical analysis. The EM forces of case EM1 were also benchmarked with results presented in [3]. Deviations are in general less than 20\% with the exception of $29 \%$ for the EM forces in one of the DCU1 Cu component due to the fact that FE models are not perfectly the same (some small features are skipped in the FE model reported in [3]). However, basically, both EM analysis results are acceptable from the engineering point of view.

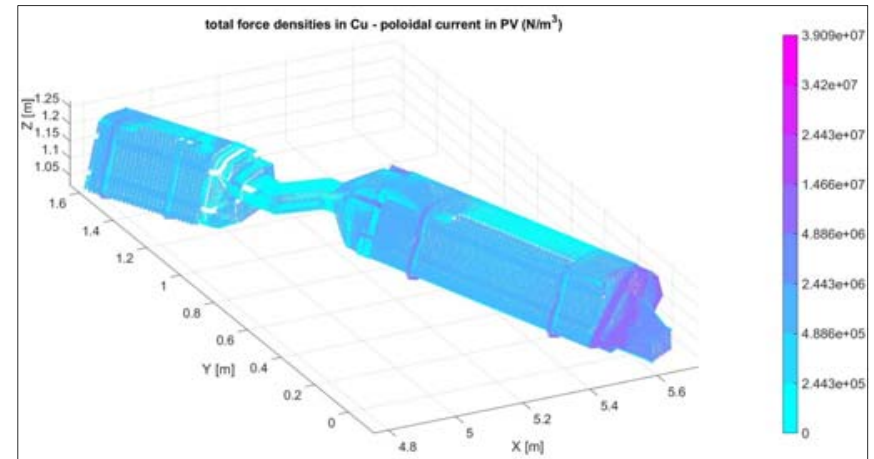

Fig. 15. Force density distribution $\left(\mathrm{N} / \mathrm{m}^{3}\right)$ in CVP Cu components during FD of SCs current and with the consideration of current sharing with PV.

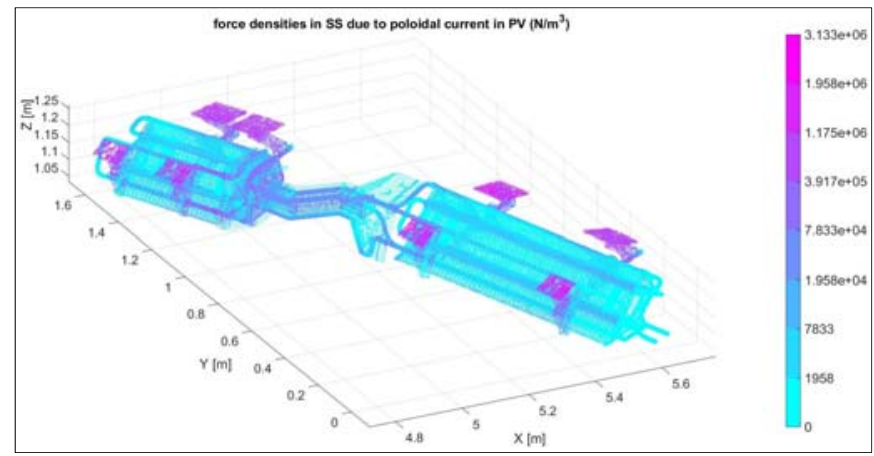

Fig. 16. Force density distribution $\left(\mathrm{N} / \mathrm{m}^{3}\right)$ in CVP SS components due to current sharing with PV (during FD of SCs current). 
TABLE V

SUMMED LORENTZ FORCES IN CU COMPONENTS (N)

\begin{tabular}{ccccc}
\hline Copper & DCU1 left Cu & DCU1 right Cu & Duct & $\begin{array}{c}\text { Single chevron in } \\
\text { DCU1 }\end{array}$ \\
\hline EM1-a & $(0.8,-16.1,1.5$, & $(-4.3,-3.5,3.6$, & $(-3.2,10.9,-$ & $(-0.028,-0.0006,-$ \\
& $16.2)^{\mathrm{a}}$ & $6.6)$ & $6.6,13.1)$ & $0.057,0.064)$ \\
EM2-a & $(0.188,-0.513$, & $(0.345,-0.034$, & $(1.056,-0.669$, & $(0.23 \mathrm{e}-3,-0.13 \mathrm{e}-3$, \\
& $0.296,0.621)$ & $0.708,0.788)$ & $-0.325,1.292)$ & $0.13 \mathrm{e}-2,0.13 \mathrm{e}-2)$ \\
EM1-a & $(1.5,-14.5,8.4$, & $(-3.9,-3.3,4.0$, & $(-3.2,10.9,-$ & $/$ \\
\& E11 & $16.8)$ & $6.5)$ & $6.6,13.1)$ & \\
& $(-0.06,0.19,-$ & $(-0.8,-0.7,1.1$, & $(-0.4,0.9,2.7$, & $/$ \\
EM3 & $0.48,0.52)$ & $1.53)$ & $2.87)$ & \\
& $(0.4,-18,-0.3$, & $(-3,-2,3,4.7)$, & $(-2,9,-5,10.5)$, & $(-0.04,0.05,0.003$, \\
EM1 ${ }^{\mathrm{b}}$ & $18), 11 \%{ }^{\mathrm{c}}$ & $29 \%$ & $20 \%$ & $0.064), 0 \%$ \\
\hline \hline
\end{tabular}

${ }^{\mathrm{a}} \mathrm{Sum}$ of Fx, Fy, Fz and Fsum in respective, in global coordinate system of W7-X.

${ }^{\mathrm{b}}$ Forces presented in [3] for benchmarking.

Deviation in percentage comparing with the presented results in [3].

\section{MECHANICAL ANALYSIS}

The temperature distribution, EM forces and dead weight (DW) are considered in mechanical analysis of the CVP. The FE model of the CVP created for thermal analysis is taken after a few modifications, such as, 1) elimination of the flexible transfer line which connected to the vacuum vessel feed through, 2) setting up the realistic contacts. The support ends attached to the PV are considered with relative displacements equivalent to PV warming up to $60{ }^{\circ} \mathrm{C}$. The temperature from the reference thermal case $\mathrm{TH} 3$, the maximum EM force densities in Cu components of case "EM1-a \& ET1", the maximum EM force densities in Cu of case EM3, and EM force densities in SS components of case ET1 are introduced into mechanical model using interpolation procedure. In order to cover the possible uncertainties due to interpolation and FE calculation, all EM force densities are scaled by factor 1.1 .

As a matter of the fact that temperature in the CVP is widely ranged from about $4 \mathrm{~K}$ to about $320{ }^{\circ} \mathrm{C}$ which require to use two different design criteria: for cold magnet components and for in-vessel components. ITER design criteria are selected for the CVP structural analysis [14-15]. According to the design criteria, stresses in the CVP are categorized as primary stress (due to dead weight and EM forces) and secondary stress (thermal stress) due to temperature gradient. Primary stress is further divided into membrane stress and bending stress, general and local stress.

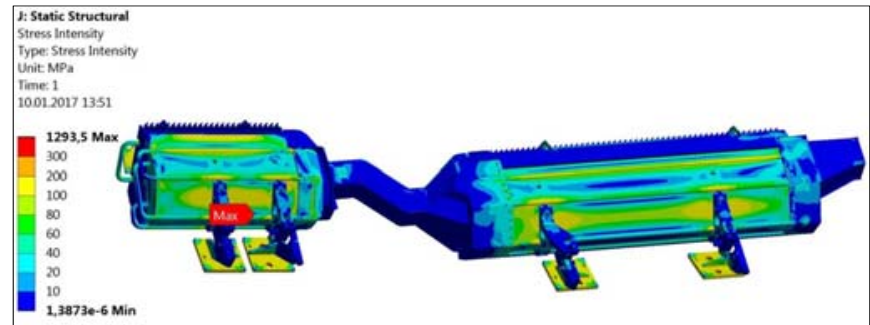

Fig. 17. Thermal stress in LN2 housing, MPa.

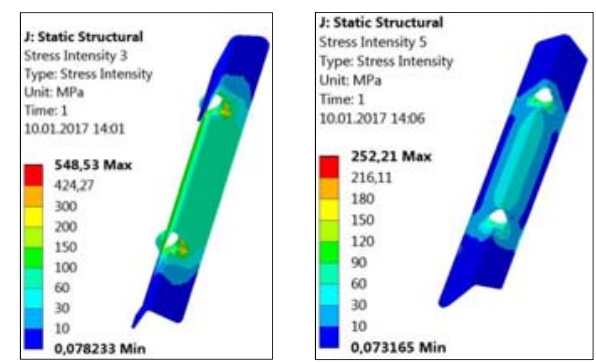

Fig. 18. Thermal stress in water chevron (left, $\mathrm{Cu}$ ) and LN2 chevron (right, SS), MPa. 
TABLE VI

\begin{tabular}{|c|c|c|c|c|c|c|c|}
\hline \multirow{2}{*}{ Position } & \multirow{2}{*}{ temperature } & \multicolumn{2}{|c|}{$\begin{array}{l}\text { Pri. Memb. } \\
(\mathrm{MPa})\end{array}$} & \multicolumn{2}{|c|}{$\begin{array}{l}\text { Pri. Memb.+Bend. } \\
(\mathrm{MPa})\end{array}$} & \multicolumn{2}{|c|}{$\begin{array}{c}\text { Pri.+Sec. } \\
(\mathrm{MPa})\end{array}$} \\
\hline & & value & limits & value & limits & value & limits \\
\hline SS chevron & $80 \mathrm{~K}$ & 52.7 & 406.7 & 77.1 & 528.7 & 335.8 & 610 \\
\hline $\mathrm{Cu}$ chevron & $120^{\circ} \mathrm{C}$ & 12.2 & 105 & 25.4 & $\begin{array}{c}\text { not } \\
\text { limited }\end{array}$ & 548.8 & $\begin{array}{c}\text { not } \\
\text { limited }\end{array}$ \\
\hline support (SS) & $80^{\circ} \mathrm{C}$ & 4.6 & 127.6 & 128.9 & $\begin{array}{c}\text { not } \\
\text { limited }\end{array}$ & / & l \\
\hline $\begin{array}{l}\text { water cooling } \\
\text { tube (SS) }\end{array}$ & $50^{\circ} \mathrm{C}$ & / & I & I & I & 446 & $\begin{array}{c}\text { not } \\
\text { limited }\end{array}$ \\
\hline DCU1 end $\mathrm{Cu}$ & $150 \mathrm{~K}$ & 73.5 & 143 & $189.3 *$ & 188.7 & $397^{*}$ & 217.7 \\
\hline
\end{tabular}

*exceed the limits due to stress concentration.

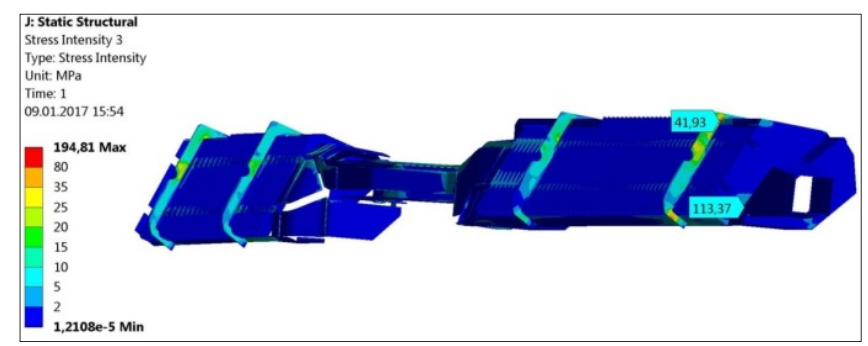

Fig. 19. Primary stresses in Cu components due to EM forces and dead weight, MPa.

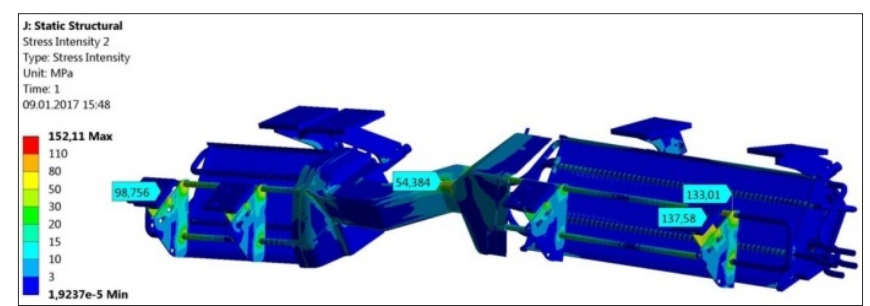

Fig. 20. Primary stresses in SS components due to EM forces and dead weight, MPa.

Fig. 17 shows the thermal stress intensity (Tresca stress) in the CVP backside area. Stress levels in LN2 housing are higher than in copper cover and transfer line due to the higher temperature gradient, but remain lower than $200 \mathrm{MPa}$. The maximum stress of more than $1200 \mathrm{MPa}$ is not realistic and represents a stress concentration located at the area of bonded contact of helium pipe to its fixation. Stress levels in supports are lower than $40 \mathrm{MPa}$, except the plates attached to the PV. Thermal stress levels in chevrons are of great concern and shown in Fig. 18. The maximum thermal stresses in water chevron are beyond $500 \mathrm{MPa}$, while about 250 MPa for LN2 chevron. They are all local stresses at the contact area attaching to the cooling pipe, and are evaluated in Table VI.

Primary stresses due to EM forces and dead weight in CVP are generally less than $30 \mathrm{MPa}$, as shown in Fig. 19 and Fig. 20, the maximum stress in $\mathrm{Cu}$ components is less than $200 \mathrm{MPa}$ due to the stress concentration at the local area of bonded contact in DCU1 end $\mathrm{Cu}$ components. The maximum primary stresses in clamps and supports are less than $50 \mathrm{MPa}$ and $150 \mathrm{MPa}$ respectively (due to current sharing with $\mathrm{PV}$ ), which are relatively higher than in other parts, but well below the stress limits.

Table VI lists the categorized stresses of some highly stressed regions and compare them with the stress limits for assessment. The stress limits are defined according to the design criteria for magnet components if the temperature is less than $20^{\circ} \mathrm{C}$, otherwise the design criteria for in-vessel components are adopted. Most of the stresses are less than the limits except the stress concentrations in DCU1 end Cu components, however, it is not an issue due to the interfaces are robustly connected. Although the primary plus secondary stress in $\mathrm{Cu}$ chevron is not limited by design criteria, it is better to ensure that high stresses of more than $500 \mathrm{MPa}$ at the interface connection between chevron and cooling pipe are withstood without the risk of detachment.

\section{CONCLUSIONS}

Complex 3D multiphysics analysis of W7-X cryopumps has been successfully performed for the demanding operation conditions.

The FE model for thermal analysis is a combination of the detailed model of the CVP and the simplified FE model of adjacent in-vessel components. It allows the accurate considerations of intricate ECRH loads, thermal 
radiation from in-vessel components backside area and loads due to plasma radiation. Heat removed by water, LN2 and liquid helium cooling circuits in different W7-X modules are estimated for optimization of the cooling capacities and thermo-hydraulic parameters of all ten CVPs. According to the calculation, the helium panel temperature will lower than $4.6 \mathrm{~K}$ if the cooling requirements are met. High heat load on LN2 cooling path of the CVPs in module 1 and 5 could be fulfilled by increasing the cooling capacity up to $2000 \mathrm{~W}$ per CVP (with mass flow rate of $11.6 \mathrm{~g} / \mathrm{s}$ and pressure drop of $1.1 \mathrm{bar}$ ).

Transient EM analysis of CVP copper components has been performed for the scenarios of fast discharge of SCs current, plasma current and trim coil current, and the alternating current in control coil. Electric analysis has been used to estimate the current sharing between the PV and the CVP due to the attachment of CVP supports to the PV. The Lorentz forces in $\mathrm{Cu}$ for the EM cases without consideration of flux densities from SCs, and the Lorentz forces in $\mathrm{Cu}$ and SS components due to the current sharing with the PV, are calculated with the approach of $\mathbf{I} \times \mathbf{B}$.

Mechanical analysis is performed with the considerations of worst case EM forces, temperature gradients from reference thermal case and the dead weight. The mechanical performance of the CVP is acceptable after the evaluation according to the ITER design criteria.

\section{ACKNOWLEDGMENT}

This work has been carried out within the framework of the EUROfusion Consortium and has received funding from the Euratom research and training programme 2014-2018 under grant agreement No 633053. The views and opinions expressed herein do not necessarily reflect those of the European Commission.

\section{REFERENCES}

[1] H. S. Bosch et al., "Transition from construction to operation phase of the wendelstein 7-X," IEEE Trans. Plasma Sci., vol. 42, no. 3, pp. 432-438, 2014.

[2] R. Stadler, A. Vorköper, J. Boscary, et al., "The in-vessel components of the experiment WENDELSTEIN 7-X," Fusion Eng. Des., vol. 84, pp. 305-308, 2009.

[3] Z. Wang, G. Ehrke, B. Mendelevitch, et al., "Structural Analysis of the W7-X Cryopump During the Superconducting Coil Fast Discharge Event," to be published in Fusion Engineering and Design.

[4] T. Eich and A. Werner, "Numerical studies on Radiative Heat Loads to Plasma-facing Components for the W7-X Stellarator," Fusion Science and Technology, vol. 53, pp. 761-779, 2008.

[5] H. Grenner, B. Böswirth et al., "Final design of W7-X divertor plasma facing components - tests and thermo-mechanical analysis of baffle prototypes," Fusion Eng. Des., vol. 66-68, pp. 447-452, 2003.

[6] Z. Wang, G. Ehrke et al., "Thermal and Mechanical Analysis of the Wendelstein 7-X cryo-vacuum pump plug-in," to be published in IEEE Transactions on Plasma Science.

[7] T. Tanabe, K. Masaki et al., "An overview of recent erosion / deposition and hydrogen retention studies in JT-60U," Phys. Scr., p. 014006, 2009.

[8] Svechnikov N. , "УГЛЕВОДОРОДНЫЕ ПЛЕНКИ В ТЕРМОЯДЕРНЫХ УСТАНОВКАХ: СТРУКТУРА И СВОЙСТВА (Hydrocarbon films in fusion devices: structure and properties)", Thesis for the Dr. degree from the National Research Center «Kurchatov Institute», Moscow, Russia, 2016 (in Russian).

[9] R. A. Haefer, "Kryo-Vakuumtechnik: Grundlagen und Anwendung,", Springer-Verlag, 1981.

[10] T. Rummel, K. Riße, et al., "The Superconducting Magnet System of the Stellarator Wendelstein 7-X," IEEE Trans. Plasma Sci., vol. 40, pp. 769-776, 2012.

[11] V. Bykov, J. Fellinger, et al., "Numerical Modelling in the Construction of Wendelstein 7-X," IEEE 25 $5^{\text {th }}$ Symposium on Fusion Engineering., pp. 769-776, 2013.

[12] F. Füllenbach, Th. Rummel, et al., "Final test of W7-X control coils power supply and its integration into the overall control environment," Fusion Eng. Des., vol. 82, pp. 1391-1395, 2007.

[13] T. Rummel, K. Riße, et al., "The Wendelstein 7-X Trim Coil System,” IEEE Trans. Appl. Supercond., vol. 24, no. 3, p. 4200904, 2014.

[14] ITER structural Design Criteria for magnet components (SDC-MC).

[15] ITER structural Design Criteria for in-vessel components (SDC-IC). 